doi:10.1016/j.ijfoodmicro.2006.01.002

Copyright (c) 2006 Elsevier B.V. All rights reserved.

\title{
Detection of noroviruses in shellfish in the Netherlands
}

\section{Ingeborg L.A. Boxman ${ }^{a, *}$ Jeroen J.H.C. Tilburga, Nathalie A.J.M. te Loeke ${ }^{a}$, Harry Vennema ${ }^{b}$, Klaas Jonker ${ }^{a}$, Enne de Boer ${ }^{a}$ and Marion Koopmans ${ }^{b}$}

${ }^{a}$ Food and Consumer Product Safety Authority, Regionale dienst Oost, P.O. Box 202, 7200 AE, Zutphen, The Netherlands

bDiagnostic Laboratory for Infectious Diseases and Perinatal Screening, National

Institute for Public Health and the Environment, P.O. Box 1, 3720 BA, Bilthoven, The Netherlands

* Corresponding author. Tel.: +31 575588100; fax: +31575588200.

\begin{abstract}
Shellfish from oyster farms in the Netherlands and imported from other European countries were examined for viral contamination. A method that allows sequence matching between noroviruses from human cases and shellfish was used. The samples of shellfish $(n=42)$ were analyzed using a semi-nested RT-PCR that had been optimized for detection of norovirus in shellfish (SR primer sets). In addition, a different genome region was targeted using a second primer set which is routinely used for diagnosis of norovirus infection in humans (JV12Y/JV13I). To improve the detection limit for this RT-PCR a semi-nested test format was developed (NV primer sets). One of 21 oyster samples (4.8\%) from Dutch farms was norovirus positive, whereas norovirus was detected in 1 out of 8 oyster samples (12.5\%) and 5 out of 13 mussel samples (38.5\%) collected directly after importation in the Netherlands. RNA from samples associated with an outbreak of gastro-enteritis in the Netherlands in 2001 was re-analyzed using the NV primer sets. At least one identical sequence (142/142 nt) was found in three fecal and in two oyster samples related to this outbreak. Further surveillance of norovirus by detection and typing of viruses from patients with gastroenteritis and shellfish is warranted to clarify the causes of future outbreaks.
\end{abstract}

\section{Introduction}

Noroviruses are the most common cause of outbreaks of acute, nonbacterial gastroenteritis in humans. The viruses can be readily transmitted via the fecaloral route, from person-to-person but also via food, water or contaminated surfaces (Koopmans and Duizer, 2004). Noroviruses are a genetically and antigenically diverse group of non-enveloped viruses belonging to a genus within the family Caliciviridae (Green et al., 2000). The norovirus genus branches into at least two distinct genogroups, GGI and GGII, based on genetic divergence in the polymerase and capsid regions (Ando et al., 2000).

Outbreaks of viral disease have been associated with the consumption of sewagecontaminated shellfish (Shieh et al., 2000). Molluscan shellfish are filter-feeders and can concentrate environmentally stable, positive-stranded RNA viruses, such as norovirus, hepatitis A virus and enterovirus, present in coastal waters (Lees, 2000). Many primer sets have been described for the detection of norovirus (Atmar and Estes, 2001). Among these, a semi-nested reverse transcriptasepolymerase chain reaction (RT-PCR) format was described which was optimized for the detection of norovirus in shellfish (Häfliger et al., 1997). However, the 
products of this assay do not overlap with the products of PCR systems commonly used for diagnosis of norovirus illness in humans. Therefore linking of clinical samples from patients with contaminated shellfish is difficult.

For that, another semi-nested RT-PCR system with NV primer sets was prepared, targeting the genomic region that is commonly used in diagnosing norovirus infection in humans. This RT-PCR system was applied in this study to RNA from oysters associated with an outbreak in February 2001 in the Netherlands. During that outbreak, 13 of 24 persons who consumed oysters fell ill with complaints of diarrhea and vomiting. Norovirus was detected in fecal and oyster samples, but with non-overlapping amplification products of the applied assays. In the present study, non-reported results of these investigations were combined with results obtained using the NV primers sets, to link the suspected oysters with findings for clinical samples.

Moreover, the two semi-nested RT-PCR systems were applied to samples of naturally contaminated shellfish. In the Netherlands, shellfish are cultured and imported both for consumption and export. Depending on the demand, a variable amount of oysters and mussels is imported from other European countries. In the present study, the presence of norovirus was monitored in samples of shellfish that were collected from farms in the Netherlands or were imported from surrounding European countries in the autumn and winter of 2003-2004.

\section{Materials and methods}

\subsection{Shellfish sampling and processing for virus and RNA extraction}

Between September 2003 and January 2004, a pooled oyster sample composed of about 20 shellfish, collected randomly, was obtained from each of 21 Dutch oyster ponds. In addition, 21 samples of shellfish harvested in other European countries were collected when the shellfish were delivered to the Dutch shellfish farms for subsequent retail sale. Thirteen mussel samples, each of about 40 shellfish, from Britain $(n=5)$, Germany $(n=4)$ or Ireland $(n=4)$ were randomly collected from batches weighing between 10 and 20 tonnes. The imported oyster samples consisted each of about 20 shellfish. Samples of oysters from Ireland $(n=2)$ and Denmark $(n=2)$ were randomly collected from batches weighing between 2 and 4 tonnes, whereas oyster samples from France $(n=4)$ were single retail packs. The samples were collected by inspectors of the Dutch Food and Consumer Product Safety Authority and stored at $-20^{\circ} \mathrm{C}$ until extraction of viruses.

About half of each sample was used for viral extraction, with from 5 to 8 oysters or 15 to 20 mussels being randomly chosen, then shucked. The stomach and digestive diverticula were isolated by dissection and pooled to obtain $5-10 \mathrm{~g}$ of tissue. Virus was extracted using a method (method C2) adapted from that of Schwab et al. (2000). Each tissue sample was homogenized by shaking at room temperature for $10 \mathrm{~min}$ in $4 \mathrm{ml}$ TriZOL LS Reagent ${ }^{\circ}$ (Invitrogen, Life Technologies, Breda, the Netherlands). After the homogenate was allowed to stand for at least $1 \mathrm{~min}$, the supernatant was collected into a $50-\mathrm{ml}$ tube. The sediment was again homogenized in an additional $4 \mathrm{ml}$ TriZOL LS Reagent $\circledast$ by shaking for $10 \mathrm{~min}$. Both TriZOL LS Reagent $\AA$ supernatants were pooled and clarified by centrifugation at $8000 \times g$, for $20 \mathrm{~min}$ at $4^{\circ} \mathrm{C}$. The aqueous interphase was stored at $-20^{\circ} \mathrm{C}$ until RNA extraction was performed according to the method described by Boom et al. (1990), using reagents of the Nuclisens Isolation Reagents kit (BioMérieux Benelux, Boxtel, the Netherlands). 
Finally, the RNA was eluted from the silica in $50 \mu \mathrm{l} 0.2 \% \mathrm{v} / \mathrm{v}$ diethylpyrocarbonate (DEPC; Sigma-Aldrich, Zwijndrecht, the Netherlands) treated water containing 1 mM dithiothreitol (DTT; Bio-Rad Laboratories, Veenendaal, the Netherlands) and $2 \mathrm{U} / \mu \mathrm{l}$ RNase inhibitor (Applied Biosystems, Nieuwerkerk aan de IJssel, the Netherlands) and stored at $-80^{\circ} \mathrm{C}$ until further analysis.

\subsection{RNA amplification}

For norovirus detection two semi-nested RT-PCR systems were applied to the samples using the previously described primer sets SRI and SRII and the primer sets NVI and NVII (Table 1). The EV03/06/05 primer set was used for detection of enterovirus. All primers for norovirus and enterovirus have been described previously (Häfliger et al., 1997, Vennema et al., 2002 and Vinjé and Koopmans, 1996) and were tested against a control panel consisting of 13 different norovirus genotypes or poliovirus 1 Sabin-1, respectively. Primers were obtained from Applied Biosystems, Nieuwerkerk aan de IJssel, the Netherlands.

-Table 1.

Primers for virus detection in shellfish samples by semi-nested RT-PCR

\begin{tabular}{|c|c|c|c|c|}
\hline Primer $^{a}$ & Sequence $5^{\prime} \rightarrow 3^{\prime}$ & Polarity & $\begin{array}{l}\text { Genomic } \\
\text { location }^{\text {b }}\end{array}$ & $\begin{array}{l}\text { Annealing temperature, } \\
\text { length (bp) }\end{array}$ \\
\hline \multicolumn{5}{|c|}{ SRI capsid gene } \\
\hline SRI-1 & CCAACCCARCCATTRTACAT & - & $5652-5671$ & $50^{\circ} \mathrm{C}, 316 \mathrm{bp}$ \\
\hline SRI-2 & AAATGATGATGGCGTCTA & + & $5356-5373$ & \\
\hline SRI-3c & AAAAYRTCACCGGGKGTAT & - & $5578-5596$ & $50^{\circ} \mathrm{C}, 241 \mathrm{bp}^{\mathrm{c}}$ \\
\hline \multicolumn{5}{|c|}{ SRII RNA polymerase } \\
\hline SRII-1 & CGCCATCTTCATTCACAAA & - & $5078-5096$ & $55^{\circ} \mathrm{C}, 514 \mathrm{bp}$ \\
\hline SRII-2 & TWCTCYTTYTATGGTGATGATGA & + & $4583-4605$ & \\
\hline SRII- $3^{\mathrm{C}}$ & TTWCCAAACCAACCWGCTG & - & $4767-4785$ & $50^{\circ} \mathrm{C}, 203 \mathrm{bp}^{\mathrm{c}}$ \\
\hline \multicolumn{5}{|c|}{ NVI RNA polymerase } \\
\hline JV13I & TCATCATCACCATAGAAIGAG & - & $4858-4878$ & $37^{\circ} \mathrm{C}, 327 \mathrm{bp}$ \\
\hline JV12Y & ATACCACTATGATGCAGAYTA & + & $4552-4572$ & \\
\hline $\mathrm{G} 1^{\mathrm{c}}$ & TCNGAAATGGATGTTGG & + & $4691-4707$ & $37^{\circ} \mathrm{C}, 187 \mathrm{bp}^{\mathrm{c}}$ \\
\hline \multicolumn{5}{|c|}{ NVII RNA polymerase } \\
\hline JV13I & TCATCATCACCATAGAAIGAG & - & $4585-4605$ & $37^{\circ} \mathrm{C}, 327 \mathrm{bp}$ \\
\hline JV12Y & ATACCACTATGATGCAGAYTA & + & $4279-4299$ & \\
\hline NoroII- $\mathrm{R}^{\mathrm{c}}$ & AGCCAGTGGGCGATGGAATTC & - & $4495-4515$ & $37^{\circ} \mathrm{C}, 236 b^{c}$ \\
\hline \multicolumn{5}{|c|}{ Enterovirus 5UTR } \\
\hline EV03 & ATTGTCACCATAAGCAGCCA & - & $582-601$ & $55^{\circ} \mathrm{C}, 438 \mathrm{bp}$ \\
\hline EV06 & CAAGCACTTCTGTTTCCCCGG & + & $164-184$ & \\
\hline $\mathrm{EVO5}^{\mathrm{c}}$ & CACGGACACCCAAAGTA & - & $547-563$ & $55^{\circ} \mathrm{C}, 400 \mathrm{bp}^{\mathrm{c}}$ \\
\hline
\end{tabular}

Mixed bases in de primers: $W=A / T, Y=C / T, R=A / G, K=G / T, M=A / C$, $\mathrm{N}=\mathrm{A} / \mathrm{T} / \mathrm{C} / \mathrm{G}, \mathrm{I}=$ inosine.

a SRI, SRII and EV primer sets were earlier published by Häfliger et al. (1997), JV12Y and JV13I by Vennema et al. (2002), G1 by Green et al. (1998). NoroII-R was based on primer NI earlier described by Green et al. (1998), but used as a reverse primer.

${ }^{b}$ In reference to Norwalk virus (M87661) (GGI), Lordsdale (X86557) (GGII) and Poliovirus type Sabine 3 (X00596) (EV).

${ }^{c}$ Combination of primers within the semi-nested PCRs were SRI-2 and SRI-3; SRII-2 and SRII-3, JV13I and G1; JV12Y and NoroII-R; EV06 and EV-05. 
All amplification steps were performed on a Master Cycler (Eppendorf, Hamburg, Germany). Twelve-and-a-half percent of total extracted RNA was reverse transcribed in RT-PCRs using the one-step Access RT-PCR kit (Promega Benelux, Leiden, the Netherlands) according to the manufacturer's protocol. Briefly, $4 \mu \mathrm{l}$ RNA extract was added to the reaction mixture $(16 \mu \mathrm{l})$ consisting of $1 \times \mathrm{AMV} / \mathrm{Tfl}$ buffer, $2 \mathrm{U}$ TfI DNA polymerase, $0.2 \mathrm{mM}$ of each dNTP, $1.5 \mathrm{mM} \mathrm{MgSO}_{4}$ and $2 \mathrm{U}$ AMV reverse transcriptase, and $15.0 \mathrm{pmol}$ of each primer. The RT reaction mixture was incubated at $48^{\circ} \mathrm{C}$ for $45 \mathrm{~min}$. The PCR amplification program consisted of an initial 3 min denaturation at $94^{\circ} \mathrm{C}$, followed by 25 cycles of denaturation at $94^{\circ} \mathrm{C}$ for $30 \mathrm{~s}$, annealing for $1 \mathrm{~min}$ at the appropriate temperature (Table 1), and extension for $1 \mathrm{~min}$ at $72^{\circ} \mathrm{C}$, with a 7 -min final extension at $72{ }^{\circ} \mathrm{C}$. For the NV primer sets, 40 amplification cycles of denaturation at $94^{\circ} \mathrm{C}$ for $60 \mathrm{~s}$, annealing at $37^{\circ} \mathrm{C}$ for $90 \mathrm{~s}$, and extension at 72 ${ }^{\circ} \mathrm{C}$ for $1 \mathrm{~min}$ were performed, with a 7 -min final extension at $72{ }^{\circ} \mathrm{C}$.

For the semi-nested PCR, $2.5 \mu$ of the completed RT-PCR reaction was added to $22.5 \mu \mathrm{l}$ reaction mixture consisting of $1 \times$ FastStart PCR buffer, $0.6 \mathrm{U}$ FastStart Taq DNA polymerase, $2.0 \mathrm{mM} \mathrm{MgCl} 2,0.25 \mathrm{mM}$ of each dNTP (all Roche Diagnostics, Almere, the Netherlands), and 12.5 pmol of each primer (Table 1 ). The semi-nested PCR amplification consisted of an initial 5 min denaturation at 94 ${ }^{\circ} \mathrm{C}$ followed by 40 cycles as described above for the SR and NV first round amplification.

All RT-PCRs included a negative control (RNA sample without target template), a positive control (sample containing the target template), and a blank control (diethylpyrocarbonate (DEPC) treated water). Dilutions of feces of patients containing either Norovirus genotype I (QueensArms) or II (Lordsdale) were used as positive controls. Serial dilutions of Poliovirus vaccine strain Sabin-1 (American Type Culture Collection) served as positive control for the enterovirus RT-PCR.

One microliter of the final PCR reaction was analyzed using the DNA 500 labchip assay of the 2100 Bioanalyzer (Agilent Technologies Nederland, Amstelveen, the Netherlands). The intensities of the signals of the positive controls, as read by the Bioanalyzer, of each run were used for comparison of results between experiments. Positive samples were analyzed by gel electrophoresis and sequencing.

\subsection{Sequence analysis of $P C R$ products from oyster samples}

After electrophoresis, bands of PCR products were extracted and purified using the High pure PCR Product Purification Kit (Roche Diagnostics). Subsequently, a cycle-sequence reaction was performed using a kit (BigDye ${ }^{\circledR}$ Terminator v3.1 cycle-sequencing kit, Applied Biosystems) according to the manufacturer's protocol. Purified PCR products were sequenced on an automated sequencer (ABI Prism 3100-Avant Genetic Analyzer, Applied Biosystems, Nieuwerkerk aan de IJssel, the Netherlands). Sequences were compared with available sequences in GenBank using the Blast program of the National Center for Biotechnology Information (NCBI) and the norovirus sequence database of the Foodborne viruses in Europe network. Sequences that were not identical $(100 \%)$ to existing entries have been submitted and accession numbers for these sequences detected in the following samples are mos-2 (AY603023); mos5 (AY603030); mos9 (AY603025, AY603026, AY603027, AY603031); mos11 (AY603024); CR17 (AY603022). 


\subsection{Statistical analyses}

A binomial regression model with logit link function was used to analyze whether the results obtained with the SR and NV primer sets were statistically significant. This model was also used to test whether the percentage of virus-contaminated oysters was different for Dutch or foreign harvesting areas.

\subsection{Analyses of fecal and oyster samples associated with an outbreak}

RNA was extracted from fecal samples from nine patients and fecal samples from nine persons without symptoms (Vennema et al., 2002). Subsequently, these RNA samples were tested for the presence of norovirus using single RT-PCRs with the JV12Y/JV13I primers (Vennema et al., 2002) or the JV12/NVp110 primers (Vinjé and Koopmans, 1996 and Le Guyader et al., 1996) followed by both direct sequence analyses and genotyping by an oligonucleotide array in a reverse line blot format (Vinjé and Koopmans, 2000) in 2001.

RNA from oysters from the same production area and with the same (CR24) or other packaging dates (CR13, 14, 16 and 17) as those associated with the outbreak were analyzed using the SR primer sets in 2001 and re-analyzed using the NV-primer sets in 2004. After sequencing, the 150 bp amplimer (NVI) was compared with the sequences obtained from the fecal samples using a multiple sequence alignment program of BioNumerics (Applied Maths, Sint-MartensLatem, Belgium) on the overlapping area (142 bp). The analyses of the oysters and fecal samples were performed, separately, at different laboratories.

\section{Results}

\subsection{Virus detection in shellfish, winter 2003-2004}

Using the genogroup-specific semi-nested RT-PCRs, norovirus RNA was detected in one of the 21 samples (4.8\%) of oysters from Dutch farms and in 6 of the 21 samples $(28.6 \%)$ of shellfish imported into the Netherlands. The positive samples of imported shellfish were 1 of 8 oyster samples (12.5\%) and 5 of 13 mussel samples $(38.5 \%)$. Of the 10 sequences detected in the positive samples seven belonged to the GGI.4 genotype, two belonged to GGIIb and one belonged to GGII.4 (Table 2).

Table 2.

Norovirus genotypes detected in 42 shellfish samples collected during winter 2003-2004

\begin{tabular}{|l|l|l|l|l|l|l|l|}
\hline \multicolumn{9}{|l|}{ Samples winter 2003-2004 } & \multicolumn{6}{l|}{ Primer sets used } \\
\hline Code & Type & Origin $^{\text {a }}$ & NVI & NVII & SRI & SRII & EV \\
\hline Oes-13 & Oysters & NL & GGI.4 ${ }^{\text {b,c }}$ & - & - & - & - \\
\hline Oes-24 & Oysters & IE & $-^{\text {d }}$ & - & - & GGII.4 & - \\
\hline Mos-11, -13 & Mussels & GB & GGI.4 & - & - & - & - \\
\hline Mos-2, $-5,-13$ & Mussels & GB & - & - & GGI.4 & - & - \\
\hline Mos-9 & Mussels & IE & GGI.4 & GGIIb & - & GGIIb & EV \\
\hline Mos-5 & Mussels & GB & - & - & - & - & EV \\
\hline Number of positive samples & 4 & 1 & 3 & 2 & 2 \\
\hline
\end{tabular}

${ }^{a}$ NL the Netherlands, IE Ireland, GB Great Britain.

${ }^{b}$ Norovirus of genogroup I or II classification (Ando et al., 2000), EV enterovirus.

${ }^{c}$ All sequences were submitted to Genbank, unless identical to existing entries. 
Sequences detected in Oes-13 and Oes-24 were $100 \%$ identical to AF472570 and AY502023, respectively.

${ }^{\mathrm{d}}(-)$ not detected.

In detail, the 2002 GGII.4 epidemic variant (Lopman et al., 2004) was detected in one oyster sample (Oes-24) originating from Ireland. Four of the five samples of mussels coming from the same production area, but harvested at different times tested positive for norovirus. In all those four samples, a GGI.4 strain was detected, three times with SRI and twice with the NVI primer set (mos-2, - 5, 11 and - 13). Multiple virus types were detected in a sample of mussels (Mos-9), including an enterovirus, which had a similarity of $96.9 \%$ to echovirus 9 and 19. One of the other samples of mussels (Mos-5) also tested positive for an enterovirus, which had a similarity of $93.3 \%$ to coxsackievirus $A 1$.

The proportion of samples that tested positive with the SR or NV primer sets, 5 $(12 \%)$ or $4(10 \%)$ of 42 , respectively, did not differ significantly $(p>0.05)$. However, of the seven samples that tested positive, only two were detected by both assays.

\subsection{The outbreak related to consumption of oysters during February 2001}

Norovirus was detected in fecal samples from eight of nine patients, but in none of the nine fecal samples from persons without symptoms. Four patients had mixed infections, including one case with three genotypes and three cases with two genotypes. The mixed infections were detected either by direct sequencing of the amplified products of the JV12Y/JV13I and JV12/NVp110 RT-PCRs, occasionally resulting in mixed norovirus sequences, or were detected by the reverse line blot assay in which amplification products hybridized with two or three genotype specific probes. These hybridization patterns indicate the presence of multiple types within one specimen as the reverse line blot assay has been shown to be genotype specific without any cross-reactivity (Vinjé and Koopmans, 2000). The norovirus genotypes detected were GGIIb (one person), the Malta genotype (GGI.4; 3 cases), a strain called Sweden Alphatron (GGIV; 2 cases), a Norwalk-like strain (GGI.1; 2 cases) and a Leeds type (GGII.7; 1 case).

Oysters samples from the same production area, with the same packing date as those consumed by patients (CR24) or other packing dates (CR13, 14, 16 and 17) were tested in 2001 using the SR primer sets. All five samples tested positive for an identical norovirus sequence belonging to GGI.4 (Table 3). RNAs from these oyster samples were re-analyzed in 2004 using the NV primer sets. Three samples tested positive (Table 3 ). One oyster sample (CR17) was positive with the NVII primers for a virus showing about $97 \%$ similarity to sequences of the GGII.7 cluster (Leeds). Two other oyster samples (CR13 and CR24) were positive for a GGI.4 virus with the NVI primers. Using a multiple sequence alignment program, this GGI.4 sequence appeared identical (142/142 nt) to the GGI.4 sequence detected in the fecal samples of three patients as detected by the JV12Y/JV13I RT-PCR. 
Table 3.

Norovirus genotypes detected in five samples of oysters from France related to an outbreak

\begin{tabular}{|l|l|l|l|l|}
\hline Oyster samples & \multicolumn{4}{|l|}{ Primer sets used } \\
\hline & NVI & NVII & SRI & SRII \\
\hline CR14, CR16 & $-^{\mathrm{a}}$ & - & $\mathrm{GGI}^{\mathrm{b}}{ }^{\mathrm{c}} \mathrm{c}$ & - \\
\hline CR13, CR24 & $\mathrm{GGI}^{\mathrm{d}}{ }^{\mathrm{d}}$ & - & ${\mathrm{GGI} .4^{\mathrm{c}}}$ & - \\
\hline CR17 & - & GGII.7 & $\mathrm{GGI}^{\mathrm{c}}{ }^{\mathrm{c}}$ & - \\
\hline Number of positive samples & 2 & 1 & 5 & 0 \\
\hline
\end{tabular}

${ }^{a}(-)$ not detected.

${ }^{b}$ Norovirus of genogroup I or II classification (Ando et al., 2000).

${ }^{c}$ Analysis revealed a sequence (205 bp) which was identical to AJ277616.

${ }^{\mathrm{d}}$ Analysis revealed a sequence (150 bp) which was identical to AF472570.

${ }^{e}$ Analysis revealed a new sequence which was submitted to Genbank

(AY603022).

\section{Discussion}

The results of the present study suggest that virus can be detected at higher percentages in import batches of oysters than in those derived from the Dutch coastal waters, though the difference was not statistically significant. Norovirus was detected more frequently in imported mussels than in imported oysters, which might be explained by a finding that noroviruses are recovered more efficiently from mussels than from oysters (Häfliger et al., 1997).

The proportion of samples that tested positive did not differ significantly between primer sets. The data did not fully overlap, so positive samples would have been missed if only one primer set had been used. Moreover, sequences obtained with the SR primer sets are comparable with sequences obtained in environmental studies (Häfliger et al., 1997 and Beuret et al., 2003), whereas sequences obtained with the NV primer sets can be compared to sequences obtained in clinical studies with the JV12Y/JV13I RT-PCR (Vinjé et al., 2003). Therefore, when sequence matching with human cases is required, the use of the NV primer sets can be recommended. Noroviruses are genetically diverse, and substantial differences in detection limits exist between PCR assays (Vinjé et al., 2003). Multiple assays may therefore be needed to detect the full range of diversity in samples.

During the winter of 2000-2001, many norovirus-associated outbreaks occurred in Europe (Buesa et al., 2002 and Nygård et al., 2003). Norovirus-contaminated oysters, which were derived from one region in France, were involved in outbreaks in Denmark, Finland (Koopmans et al., 2003a) and in the Netherlands (present study). In the latter outbreak multiple norovirus types were detected in the patients, with some of them having mixed infections, as was previously reported for other oyster-related outbreaks (Sugieda et al., 1996 and Gallimore et al., 2005). Among the norovirus genotypes detected in the fecal samples in the present study was GGIIb, which was also detected in other European outbreaks (Buesa et al., 2002 and Nygård et al., 2003), the Malta genotype (GGI.4) and a Leeds type (GGII.7). A sequence belonging to the latter GGII.7 cluster was also detected in one of the oysters. Sequence comparison could, however, not be performed, since this particular type was only detected using the reverse line blot assay in the patient sample and could not be sequenced. The Malta genotype (GGI.4) detected in three cases appeared to be identical (142/142 nt) to the 
GGI.4 sequence detected in two oyster samples. This finding supports the view that contaminated shellfish may serve as vehicles for norovirus transmission.

Linking cases of viral disease to contaminated food is an ultimate goal of our work (Shieh et al., 2000 and Le Guyader et al., 2003), but the data illustrate the difficulty of doing this. Finding dissimilar sequences does not necessarily rule out a link if multiple variants are present in a food item. Conversely, finding identical sequences is not always proof of a link. Often multiple lineages of norovirus circulate together in the community, but occasionally a single variant predominates (Koopmans et al., 2003b). This was observed in 1996 and more recently in 2002, when a GGII.4 variant emerged which caused a large majority of the outbreaks during that year (Lopman et al., 2004). In such a situation, finding identical GGII.4 sequences in patients and foods does not prove that they are linked. Finding identical sequences of a rare genotype is much more informative. In this respect, it is intriguing to note that the majority of strains identified in the oysters in this study belong to GGI, whereas most human disease is caused by GGII strains (Koopmans et al., 2003a). This suggests that "disease tracking" by sequence matching is a promising approach to determine the cause of norovirus disease associated with shellfish consumption. It also suggests possible differences in the properties of noroviruses of different genogroups, such as relatively high stability in the water environments for GGI, and the possible presence of an environmental reservoir.

As viral contaminated shellfish can serve as the vehicle for norovirus transmission, and can be expected to cause further outbreaks, continued surveillance of norovirus and typing by sequencing in patients with gastroenteritis and shellfish from coastal waters is warranted.

\section{Acknowledgements}

We would like to thank the inspectors of the Dutch Food and Consumer Product Safety Authority for collection of shellfish samples and Dr. A. Vollema for performing statistical analyses on the data. 


\section{References}

Ando et al., 2000 T. Ando, J.S. Noel and R.L. Fankhauser, Genetic classification of "Norwalk-like viruses", The Journal of Infectious Diseases 181 (2000), pp. S336-S348.

Atmar and Estes, 2001 R.L. Atmar and M.K. Estes, Diagnosis of noncultivatable gastroenteritis viruses, the human caliciviruses, Clinical Microbiology Reviews 14 (2001), pp. 15-37.

Beuret et al., 2003 C. Beuret, A. Baumgartner and J. Schluep, Virus-contaminated oysters: a threemonth monitoring of oysters imported to Switzerland, Applied and Environmental Microbiology 69 (2003), pp. 2292-2297.

Boom et al., 1990 R. Boom, C.J.A Sol, M.M.M. Salimans, C.L. Jansen, P.M.E. Wertheim-Dillen and J. van der Noordaa, Rapid and simple method for purification of nucleic acids, Journal of Clinical Microbiology 28 (1990), pp. 495-503.

Buesa et al., 2002 J. Buesa, B. Collado, P. López-Andújar, R. Abu-Mallouh, J. Rodríguez Díaz, A. García Díaz, J. Prat, S. Guix, T. Llovet, G. Prats and A. Bosch, Molecular epidemiology of caliciviruses causing outbreaks and sporadic cases of acute gastroenteritis in Spain, Journal of Clinical Microbiology 40 (2002), pp. 2854-2859.

Gallimore et al., 2005 C.I. Gallimore, J.S. Cheesbrough, K. Lambden, C. Bingham and J.J. Gray, Multiple norovirus genotypes characterised from an oyster-associated outbreak of gastroenteritis, International Journal of Food Microbiology 103 (2005), pp. 323-330.

Green et al., 1998 J. Green, K. Henshilwood, C.I. Gallimore, D.W.G. Brown and D.N. Lees, A nested reverse transcriptase PCR assay for detection of small round-structured viruses in environmentally contaminated molluscan shellfish, Applied and Environmental Microbiology 64 (1998), pp. 858-863.

Green et al., 2000 K.Y. Green, T. Ando, M.S. Balayan, T. Berke, I.N. Clarke, M.K. Estes, D.O. Matson, S. Nakata, J.D. Neill, M.J. Studdert and H.-J. Thiel, Taxonomy of the caliciviruses, The Journal of Infectious Diseases 181 (2000), pp. S322-S330.

Häfliger et al., 1997 D. Häfliger, M. Gilgen, J. Lüthy and Ph. Hübner, Seminested RT-PCR systems for small round structured viruses and detection of enteric viruses in seafood, International Journal of Food Microbiology 37 (1997), pp. 27-36.

Koopmans and Duizer, 2004 M. Koopmans and E. Duizer, Foodborne viruses: an emerging problem, International Journal of Food Microbiology 90 (2004), pp. 23-41.

Koopmans et al., 2003a M. Koopmans et al. and for the European Consortium on Foodborne Viruses, Early identification of common-source foodborne virus outbreaks in Europe, Emerging Infectious Diseases 9 (2003), pp. 1136-1142.

Koopmans et al., 2003b M.P.G. Koopmans, E. van Strien and H. Vennema, Molecular epidemiology of human caliciviruses. In: U. Desselberger and J. Gray, Editors, Viral Gastroenteritis vol. 9, Elsevier BV, Amsterdam (2003), pp. 523-554.

Le Guyader et al., 1996 F.S. Le Guyader, M.K. Estes, M.E. Hardy, F.H. Neill, J. Green, D.W. Brown and R.L. Atmar, Evaluation of a degenerate primer for the PCR detection of human caliciviruses, Archives of Virology 141 (1996), pp. 2225-2235.

Le Guyader et al., 2003 F.S. Le Guyader, F.H. Neill, E. Dubois, F. Bon, F. Loisy, E. Kohli, M. Pommepuy and R.L. Atmar, A semiquantitative approach to estimate Norwalk-like virus contamination of oysters implicated in an outbreak, International Journal of Food Microbiology 87 (2003), pp. 107112.

Lees, 2000 D. Lees, Viruses and bivalve shellfish, International Journal Food Microbiology 59 (2000), pp. $81-116$.

Lopman et al., 2004 B. Lopman et al. and for the European Foodborne Viruses network, Increase in viral gastroenteritis outbreaks in Europe and epidemic spread of new norovirus variant, Lancet 363 (2004), pp. 682-688. 
Nygård et al., 2003 K. Nygård, M. Torvén, C. Ancker, S.B. Knauth, K.-O. Hedlund, J. Giesecke, Y. Andersson and L. Svennson, Emerging genotype (GGIIb) of norovirus in drinking water, Sweden, Emerging Infectious Diseases 9 (2003), pp. 1548-1552.

Schwab et al., 2000 K.J. Schwab, F.H. Neill, R.L. Fankhauser, N.A. Daniels, S.S. Monroe, D.A. Bergmire-Sweat, M.K. Estes and R.L. Atmar, Development of methods to detect "Norwalk-like viruses" (NLVs) and hepatitis a virus in delicatessen foods: application to a food-borne NLV outbreak, Applied and Environmental Microbiology 66 (2000), pp. 213-218.

Shieh et al., 2000 Y. Shieh, S.S. Monroe, R.L. Fankhauser, G.W. Langlois, W. Burkhardt III and R.S. Baric, Detection of norwalk-like virus in shellfish implicated in illness, The Journal of Infectious Diseases 181 (2000), pp. S360-S366.

Sugieda et al., 1996 M. Sugieda, K. Nakajima and S. Nakajima, Outbreaks of Norwalk-like virusassociated gastroenteritis traced to shellfish: coexistence of two genotypes in one specimen, Epidemiology and Infection 116 (1996), pp. 339-346.

Vennema et al., $2002 \mathrm{H}$. Vennema, E. de Bruin and M. Koopmans, Rational optimization of generic primers used for Norwalk-like virus detection by reverse transcriptase polymerase chain reaction, Journal of Clinical Virology 25 (2002), pp. 233-235.

Vinjé and Koopmans, 1996 J. Vinjé and M.P. Koopmans, Molecular detection and epidemiology of small round-structured viruses in outbreaks of gastroenteritis in the Netherlands, The Journal of Infectious Diseases 174 (1996), pp. 610-615.

Vinjé and Koopmans, 2000 J. Vinjé and M.P.G. Koopmans, Simultaneous detection and genotyping of "Norwalk-like viruses" by oligonucleotide array in a reverse line blot hybridization format, Journal of Clinical Virology 38 (2000), pp. 2595-2601.

Vinjé et al., 2003 J. Vinjé, H. Vennema, L. Maunula, C.H. von Bonsdorff, M. Hoehne, E. Schreier, A. Richards, J. Green, D. Brown, S.S. Beard, S.S. Monroe, E. de Bruin, L. Svensson and M.P.G. Koopmans, International collaborative study to compare reverse transcriptase PCR assays for detection and genotyping of noroviruses, Journal of Clinical Virology 41 (2003), pp. 1423-1433. 